\title{
Avaliação dos impactos ambientais na Lagoa do Araçá, Recife, Pernambuco, Brasil
}

\author{
José Gustavo da Silva Meloa, Elisabeth Regina Alves Cavalcanti Silvab, Daniella Roberta Silva de Assis ${ }^{\mathrm{b}}$ \\ a Grupo de Estudos em Meio Ambiente, Universidade Federal de Pernambuco, Recife, CEP: 53444-530, Pernambuco, Brasil. \\ * josegustavo_melo@hotmail.com \\ b Programa de Pós-Graduação em Desenvolvimento e Meio Ambiente, Universidade Federal de Pernambuco, Recife, CEP: 50.670-900, Pernambuco, \\ Brasil.
}

Recebido: 20 novembro 2017 / Aceito: 08 janeiro 2018 / Publicado online: 20 janeiro 2018

\begin{abstract}
Resumo
Esta pesquisa teve como objetivo identificar, quantificar e qualificar os impactos ambientais antrópicos, decorrente dos processos de urbanização em torno da Lagoa do Aracá, Recife, Pernambuco. Os impactos foram investigados, sendo dividida em três setores (SI, SII e SIII) por meio de checklist, que contém uma lista de indicadores ambientais e antrópicos, esses indicadores com os pesos e efeitos do impacto, fornecendo como resultado um valor negativo da classe de impacto. Além da análise dos processos de urbanização que causaram impactos ambientais, com a avaliação das condições do ecossistema manguezal. A Lagoa do Araçá tem sido submetida a várias ações antropogênicas, que têm provocado alterações degradantes, porém, com efeito pequeno (Setores I: -49 e III: -78) e moderado (Setor II: -106) em sua fisiografia. Consequentemente, a causa de várias intervenções impactantes, com pouco planejamento, provocou modificações impactantes que variaram de pequeno a moderado. Todavia, a ação dos impactos antrópicos induzidos pelo homem, somado aos tensores naturais que atuam sobre o ecossistema manguezal, limitam o desenvolvimento do bosque de mangue. Diante disso, as ações antrópicas, decorrentes da urbanização, avançam sobre o meio natural, exigindo medidas preventivas e emergenciais para a conservação da Lagoa do Araçá.
\end{abstract}

Palavras-chave: Manguezal, degradação, ação antrópica, checklist.

\section{Environmental impacts in Araçá Lagoon, Recife, Pernambuco, Brazil}

\begin{abstract}
The objective of this research was to identify, quantify and qualify the anthropic environmental impacts resulting from the urbanization processes around the Aracá Lagoon, Recife, Pernambuco. The impacts were investigated, being divided into three sectors (SI, SII and SIII) through a checklist, which contains a list of environmental and anthropic indicators, these indicators with impact weights and effects, resulting in a negative value of the class of impact. Besides the analysis of urbanization processes that caused environmental impacts, with the evaluation of the conditions of the mangrove ecosystem. The Araçá Lagoon has been subjected to several anthropogenic actions, which have caused degrading alterations, but with small effect (Sectors I: -49 and III: -78) and moderate (Sector II: -106) in its physiography. Consequently, the cause of several shocking interventions, with little planning, led to shocking modifications ranging from small to moderate. However, the action of maninduced anthropic impacts, coupled with the natural stressors acting on the mangrove ecosystem, limit the development of the mangrove forest. In view of this, the anthropic actions, arising from urbanization, advance on the natural environment, requiring preventive and emergency measures for the conservation of Araçá Lagoon.
\end{abstract}

Keywords: Mangrove, degradation, anthropic action, checklist.

\section{Introdução}

A modificação das relações entre o campo e a cidade é essencial para a compreensão do fenômeno da urbanização (Schaeffer-Novelli et al., 2012). No Brasil, o êxodo rural aconteceu acelerada e desordenadamente a partir da segunda guerra mundial. A população urbana passou de, aproximadamente, $16 \%$ (1920), para $80 \%$ (2000) e $84,4 \%$
(2010; Coelho-Jr, 2010).

No processo de urbanização, a especulação imobiliária e o acúmulo do capital são fatores influenciadores que, muitas vezes, não considera a qualidade de vida para o indivíduo e/ou ao ambiente (Barbosa et al., 2012; Zancheti e Hidaka, 2014). Desta forma, ao longo do tempo a paisagem urbana tem sido alterada por condições degradantes e modificadoras do meio 
natural (Rech e Rech, 2010).

O processo de urbanização em Recife se inicio em 1820. Como cidade, Recife passou por intensas modificações, tais como a iluminação das ruas, o abastecimento de água com a implantação do projeto da companhia Beberibe, o transporte público que era feito por meio de carroças e liteiras e, a partir de 1860, foi implantado o sistema ferroviário que ligava o centro da cidade a localidades adjacentes (Sant'anna, 1995). Nesse contexto, A Lagoa do Araçá, localizada em Recife, desponta como área ambiental a ser preservada, estando sujeita aos efeitos da poluição.

Por outro lado, os elementos para a compreensão do comportamento dos dados biológicos, frente aos processos degradantes da urbanização, nos manguezais, vegetação dominante na Lagoa, são imprescindíveis como subsídios para a análise do comportamento dos impactos ambientais na área. Tal alteração do espaço atua como modificador da dinâmica natural na área (Zancheti e Hidaka, 2014).

Logo, a ocupação das áreas próximas a lagoas, hoje consideradas de risco, assim como as encostas, se deu além do crescimento populacional, pela expulsão da parcela da população mais carentes das áreas centrais da cidade, que começavam a atrair o interesse do setor imobiliário, a demolição dos mocambos, aterramento de áreas de mangues, ocupação de morros a noroeste sem nenhum planejamento (Barbosa et al., 2012).

A retirada da população menos favorecida foi intensificada a partir dos anos 60 e 70, com intervenção estatal, essa mancha urbana creceu desordenadamente nas áreas de morro nas áreas planas da cidade e acarretando problemas ambientais graves (Pereira e Melo, 2008).
Esta pesquisa objetivou identificar, quantificar e qualificar os impactos ambientais antrópicos, decorrente dos processos de urbanização em torno da Lagoa do Aracá, Recife, Pernambuco.

\section{Material e métodos}

\section{Caracterização da Área de Estudo}

A Lagoa do Araçá está localizada na porção sul da cidade do Recife, no bairro da Imbiribeira, entre as coordenadas de 0289155L e $9105013 \mathrm{~N}$, UTM e geográficas $08^{\circ} 05^{\prime} 38^{\prime \prime} \mathrm{S}$ e $34^{\circ} 54^{\prime} 54^{\prime \prime} \mathrm{W}$ a $8^{\circ} 05^{\prime} 47^{\prime \prime} \mathrm{S}$ e $34^{\circ} 54^{\prime} 64^{\prime \prime} \mathrm{W}$ (Figura 1), em uma área populosa e considerada de alto padrão econômico, inserida na região Metropolitana do Recife, também é uma região de mangues. Os manguezais que se desenvolvem nesta localidade sofrem ameaça de deterioração, tanto pelo acúmulo do lixo como pelas ocupações espontâneas e desorganizadas, o que apressa seu processo de degradação.

A Lagoa é uma área de mangue, caracterizada por possuir um clima tropical úmido, tipo Ams (segundo Koppen), com chuvas de outono-inverno e um período seco primaveraverão. Sua temperatura atinge a média de $25^{\circ} \mathrm{C}$, com pequenas variações (Rolim et al., 2007). Esse "microclima" se deve, além de outros motivos, à presença de vários rios, da própria Lagoa e de ventos alísios, que trazem brisas suaves para a região.

$\mathrm{Na}$ área de estudo predominam os solos indiscriminados de mangue, compreendendo solos holocênicos, halomórficos e alagados, com textura variando de argilosa a arenosa (Cuzzuol; Rocha, 2012; Bermini; Rezende, 2010; Castro, 2005).
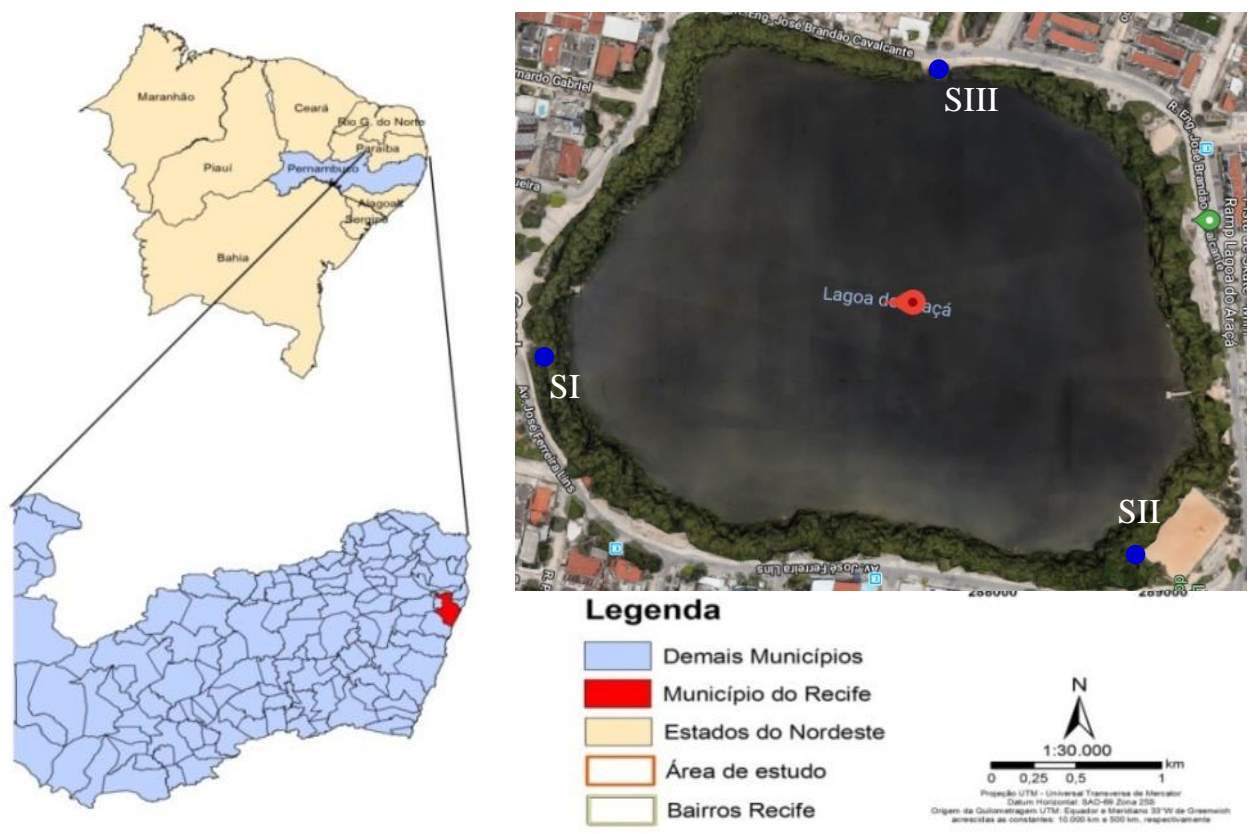

Figura 1. Localização dos setores onde forem aplicados os checklist. Fonte: Adaptado do Google Earth (2017). 


\section{Desenho Amostral}

Para a pesquisa in loco, a região da Lagoa do Araçá foi dividida em três setores, que foram delimitados através de visita piloto, onde dois critérios (Acessibilidade e disposição entre os setores) contribuíram para escolha dos pontos de coletas de dados. Esses critérios levaram em conta a localização da Lagoa e configuração dessa em imagens digitais. Os setores foram dispostos assim: I - $\left(8^{\circ} 05^{\prime} 38^{\prime \prime} \mathrm{S}\right.$;

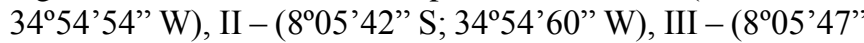
S; 3454"64" W; Figura 1).

Em cada setor, foram realizadas três (3) visitas (duas por mês, nos meses: 07/2016; 08/2016 e 09/2016) para observação in loco e aplicação de checklist, ao longo do segundo semestre de 2016, ou seja, de julho a setembro.

\section{Instrumentos de coleta de dados}

O procedimento metodológico empregado na avaliação e quantificação dos impactos ambientais foi à aplicação de um checklist, orientado pelo método Indutivo, pois a observação dos fatos tal como ocorrem, não permite isolar e controlar as variáveis, mas perceber e estudar as relações estabelecidas. Os processos mentais partem de dados particulares, satisfatoriamente constatados, para inferir uma verdade geral ou universal, não contida nas partes examinadas, pois a indução parte de um fenômeno para chegar a uma lei geral, por meio da observação e de experimentação (Mezzaroba; Monteiro, 2014).

Para se realizar a avaliação de impacto ambiental, por meio de checklist, deve-se seguir a metodologia, pois essa consiste em um conjunto de normas que variam de acordo com o fator ambiental considerado, além de ser um método flexível, aplicável em qualquer fase do processo de análise ambiental e revisado constantemente (Cremonez et al., 2014; Ferreira et al., 2010).

O Checklist visa à identificação dos impactos ambientais, seus efeitos negativos, com a finalidade de subsidiar alternativas de ação, na relação entre a utilização dos recursos ambientais e a manutenção ou a melhoria do seu padrão ambiental, proporcionando uma leitura e a definição clara quanto aos possíveis comprometimentos dos recursos ambientais (Cremonez et al., 2014).

A checklist, sua aplicação e classificação, descrita neste artigo, para avaliar os principais impactos ambientais na área de estudo, seguem a metodologia de Tommasi (1994). Foram considerados XX aspectos, foram eles: Expansão urbana, Caminhos nos manguezais, Deposição de resíduos sólidos (Lixo), Degradação da vegetação, Morte do manguezal, Emissão de efluentes domésticos (Mangue), Recreação (Mangue), Pesca (Manguezal), Pontes, Irrigação (Rio), Obstrução do canal, Abertura artificial do estuário. Cada impacto investigado no checklist foi pontuado com um os seguintes pesos: 1 (pequeno), 3 (moderado) ou 5 (extremo).

Os impactos extremos foram aqueles que interferiam de forma abrangente e extensa em cada ambiente, os moderados, foram todos aqueles que, mesmo sendo expressivos tinham características mais pontuais e; os pequenos foram os que descaracterizavam o ambiente, mas não o degradava.

Os efeitos dos impactos também receberam valor, porém notas negativas $(-1,-3,-5)$, dependendo de sua intensidade, ou com nota zero (0), quando ausentes. Os resultados da multiplicação dos pesos atribuídos aos impactos pelas notas de seus efeitos permitiram classificar cada impacto nas seguintes categorias: pequeno (valores de -1 a -3 ) moderado (valores -5 a -9) e extremo (valores -15 a -25). O somatório dos valores desta multiplicação fornece o índice geral de impacto no estuário estudado, sendo considerado pequeno (-1 a -100$)$, moderado (-100 a -170$)$ e extremo (-171 ou mais).

\section{Resultados e discussão}

Os valores reportados para o checklist aplicado nos três setores investigados, na Lagoa do Araçá, estão descritos na Tabela 1.

No Setor I, foi constatado que a expansão urbana, a deposição de efluentes domésticos e/ou industriais, foram os índices de impactos que obtiveram os valores mais elevados.

Tabela 1. Checklist dos impactos ambientais nos três setores investigados na Lagoa do Araçá, Recife, Pernambuco.

\begin{tabular}{|c|c|c|c|c|c|c|c|c|c|}
\hline \multirow{2}{*}{ Indicador } & \multicolumn{3}{|c|}{ Setor I } & \multicolumn{3}{|c|}{ Setor II } & \multicolumn{3}{|c|}{ Setor III } \\
\hline & Peso & Efeito & Classe & Peso & Efeito & Classe & Peso & Efeito & Classe \\
\hline Expansão urbana & 3 & -5 & -15 & 3 & -5 & -15 & 3 & -3 & -9 \\
\hline Caminhos nos manguezais & 1 & -1 & -1 & 1 & -1 & -1 & 0 & 0 & 0 \\
\hline Deposição de resíduos sólidos (Lixo) & 1 & -1 & -1 & 5 & -5 & -25 & 3 & -3 & -9 \\
\hline Degradação da vegetação & 3 & -1 & -3 & 3 & -3 & -9 & 3 & -3 & -9 \\
\hline Morte do manguezal & 1 & -1 & -1 & 1 & -1 & -1 & 0 & 0 & 0 \\
\hline Emissão de efluentes domésticos* & 5 & -5 & -25 & 5 & -5 & -25 & 5 & -5 & -25 \\
\hline Recreação (Mangue) & 1 & -1 & -1 & 1 & -1 & -1 & 5 & -5 & -25 \\
\hline Pesca (Manguezal) & 1 & -1 & -1 & 3 & -3 & -9 & 1 & -1 & -1 \\
\hline Pontes & 1 & -1 & -1 & 1 & -1 & -1 & 0 & 0 & 0 \\
\hline Irrigação (Rio) & 0 & 0 & 0 & 3 & -3 & -9 & 0 & 0 & 0 \\
\hline Obstrução do canal & 0 & 0 & 0 & 1 & -1 & -1 & 0 & 0 & 0 \\
\hline Abertura artificial do estuário & 0 & 0 & 0 & 3 & -3 & -9 & 0 & 0 & 0 \\
\hline Total & & & -49 & & & -106 & & & -78 \\
\hline
\end{tabular}

* No mangue. Os indicadores com valores iguais a zero indicam que não foram observados no setor. 
A Figura 3 evidência a coloração amarronzada típica de matéria orgânica provenientes dos efluentes domésticos despejados pelas manilhas de tubulação de saneamento básico (boca de lodo). Apesar disto, o trecho inclui-se na classe de impacto pequeno (-49), o que pode ser justificado pelos indicadores não terem obtido pesos e efeitos elevados.

Constatou-se que a lagoa possuía 17 pontes de despejo de esgoto de tamanhos variáveis, despejando efluentes sanitários e pluviais além de 11 tubulações de esgoto vertendo seus efluentes no canal de comunicação da lagoa com o Rio Tejipió (Figura 3).

De acordo com algumas pesquisas (Schaeffer-Novelli et al., 2012; Bernini e Rezende, 2010; Coelho-Jr, 2010), os níveis de poluição da Bacia do Rio Tejipió, principal alimentador da Lagoa do Araçá, estão muito acima daqueles permitidos pela legislação ambiental, com taxas de Oxigênio dissolvido que variam de 0 a $1 \mathrm{mg} \mathrm{L}^{-1}$ e de Demanda Bioquímica de Oxigênio entre 40 e $55 \mathrm{mg} \mathrm{L}^{-1}$, quando a legislação fixa os valores máximos de $4 \mathrm{mg} \mathrm{L}^{-1}$ e de $10 \mathrm{mg} \mathrm{L}^{-1}$, respectivamente, (Pereira e Melo, 2008; Monteiro, 2007).

A poluição química, despejo de efluentes domésticos e industriais no estuário do rio Tejipió provocam níveis elevados de matéria orgânica particulada em suspensão e baixos índices de oxigênio dissolvido na água, com mortandade consequente cíclica (geralmente no verão) de peixes e crustáceos (Bernini e Rezende, 2010).

Os principais impactos ambientais observados nos três Setores investigados foram: expansão urbana, aterro do manguezal, quantidade considerável de resíduos sólidos, tanto na água como nas margens, e lançamento de efluentes domésticos. Estes indicadores de degradação estão espalhados, por toda a extensão da área pesquisada.

De acordo, com pesquisas feitas por Meirelles et al. (2007), o ecossistema suporta inúmeros e intensos impactos, oriundos dos problemas comuns de boa parte das metrópoles brasileiras, como, a desigualdades sociais, concentração populacional nas áreas de morros e margens dos Rios, expansão urbana desordenada, além da degradação dos recursos naturais.

Para Coelho-Jr (2010), essa ocupação ocorre muitas vezes, sobre as margens dos rios e dos manguezais através de agentes que provocam graves alterações na rede de drenagem, como o desaparecimento de alguns canais e a artificialização de outros, além dos cortes da vegetação do mangue, para a construção de cercas.

No setor II, foi identificado que a expansão urbana, a deposição de resíduos sólidos, e emissão de efluentes domésticos e a degradação da vegetação foram os indicadores de impactos que mais contribuíram para a degradação da Lagoa do Araçá, seguidos da pesca que é mais intensa nesse Setor e de outros indicadores (Tabelas 2).

A atividade de pesca é maior, pois nas áreas é encontrada a espécie Centropomus ensiferus (Poey, 1860), conhecida como camorim ou Camurim, que é apreciada pelo sabor agradável.

Nesse setor, encontrou-se grades para impedir a passagem do resíduos depositado nas águas do rio Tejipió (Figura 3A). Nesta região está o encontro do rio Tejipió e a lagoa, bem como o mirante de pesca (Figura 3B) e é ponto de pesca e o checklist reportou impacto foi considerado moderado (-106; Tabela 1).

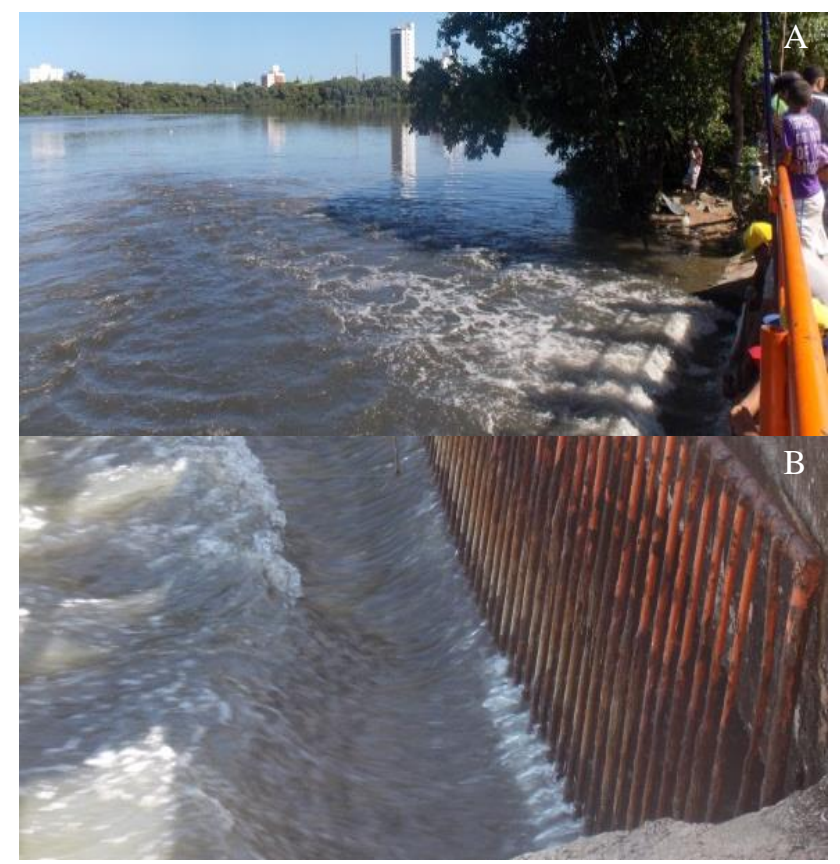

Figura 3. Grade que "impede" a entrada de resíduos, oriundo do rio Tejipió, (A); e mirante de pesca, (B).

Trabalhando no inventário dos diferentes tipos de impactos antropogênicos, no estuário do rio Timbó/PE, Cabral; Sassi e Costa (2005) utilizaram um modelo de checklist adaptado para esse ecossistema, com a intenção de processar os modificadores da paisagem, analisando as duas margens do estuário para encontrar os diferentes indicadores de degradação, como: invasões de áreas públicas, cortes da vegetação do mangue, agricultura, no entorno do ambiente estudado.

No setor III, observou-se que a existência de expansão urbana, degradação da vegetação, deposição de resíduos sólidos, entre outros, mas os que obtiveram maior valor, no tocante ao impacto ambiental, forma: emissão de efluentes domésticos e a recreação, pois é nessa área que se encontra a praça de eventos da Lagoa do Araçá, justificando assim, os níveis elevados. $\mathrm{O}$ referido trecho teve o índice geral considerado de impacto pequeno (-78; Tabela 1).

Portanto, dentre os três setores analisados, dois apresentaram índices gerais de impacto considerado pequeno (Setor I = -49 e Setor III = -78) e moderado (Setor II = -106).

Para Moura e Oliveira (2009) e Meireles et al. (2007), as condições do ambiente devem ser avaliadas, através de instrumentos que atuem de forma preventiva na avaliação de impactos no espaço que estejam sofrendo pressões e modificações, com vista a evitar a propagação destes processos geradores de degradação.

Segundo Barbosa et al. (2012) e Cuzzoul e Rocha (2012) muitas áreas de manguezal vêm sofrendo processos de desestruturação em diversos níveis, decorrentes da ação antrópica, não só em função da exploração indiscriminada de sua fauna e flora, como também pela contaminação de suas águas, por efluentes sem tratamento, entulho, dentre outros. 
Atualmente pôde se observar que a expansão urbana, da cidade do Recife, se deve ao avanço, desta sobre os espaços naturais, outrora ocupadas pelo ecossistema.

Por conseguinte, há um desequilíbrio ecológico no bosque de manguezal da Lagoa do Araçá, porém com impacto ambiental pequeno (I: -49; III: -78), na maioria dos setores avaliados, possivelmente provocado, pelas ações antropogênicas decorrentes do crescimento urbano desordenado, especulação imobiliária e da falta de planejamento para minorar os impactos oriundos do impulso predatório do homem, frente à crescente demanda por espaço, motivado pelos processos de urbanização.

Na Lagoa do Araçá foram observados diversos indicadores de degradação ambiental, que causaram alterações nas propriedades físicas, químicas e biológicas no manguezal, foram eles: aterro para construção e pavimentação, deposição de lixo, efluentes domésticos e/ou industriais, além da expansão urbana, fruto da especulação imobiliária.

Foram identificadas 14 empresas nas proximidades, dentre as quais, 4 (2 Lanchonete e 2 Restaurantes) poluíam a lagoa com óleo vegetal usado na fritura, assim como no preparo de alimentos, despejado junto com as águas servidas do sistema de esgotamento sanitário dos estabelecimentos comerciais destacados. Visto que, esses empreendimentos não fazem o descarte apropriado do óleo usado, tampouco tem programa de reciclagem deste material. Além do despejo de efluentes domésticos, oriundos dos domicílios localizados no entorno da lagoa tinham esgotamento sanitário inadequado.

Desta forma, os processos geradores de impactos ambientais derivam da ação antrópicas ou do conjugado delas realizadas em um determinado ponto (Coelho-Jr, 2010). Sendo assim, compreendemos, através de dados quantitativos, que a Lagoa do Araçá tem sido submetida a várias ações antropogênicas, que têm provocado alterações degradantes, porém, com efeito pequeno (Setores I: -49 e III: -78) e moderado (Setor II: -106) em sua fisiografia (Tabela 5).

Contudo, a ação dos impactos antrópicos induzidos pelo homem, somada à dos tensores naturais que atuam sobre o ecossistema manguezal, limitam o desenvolvimento do bosque de mangue, interferindo tanto na estrutura como na diversidade, eliminando aquelas espécies mais sensíveis (Schaeffer-Novelli et al., 2012).

\section{Conclusões}

O nível de degradação ambiental na Lagoa do Araçá foram considerado pequeno e moderado, constatados através dos índices gerais de impacto ambientais, obtidos nos setores analisados, onde a maior parte apresentou índices baixos.

Portanto, nos três setores observados, a urbanização avança sobre o meio natural pondo em risco os recursos naturais da lagoa, necessitando de medidas preventivas e emergenciais para conservar a lagoa do Araçá. Neste momento, o grande desafio é a dificuldade de lidar e cuidar com a multiplicidade de interesses para a gestão da Lagoa do Araçá.

\section{Referências}

Barbosa, E. M.; Barata, M. M. L.; Hacon, S. S. A. 2012. Saúde no licenciamento ambiental: uma proposta metodológica para a avaliação dos impactos da indústria de petróleo e gás. Ciência \& Saúde Coletiva, 17(2): 299-310.

Bernini, E.; Rezende, C.E. 2010. Concentração de nutrients em folhas e sedimentos em um manguezal do norte do estado do Rio de Janeiro. Revista Gestão Costeira Integrada, 2: 1-10.

Cabral, A.L.; Sasso, R.; Costa, C.F. 2005. Estuários do nordeste do Brasil e o desenvolvimento sustentável: usos múltiplos e impactos do rio Timbó, como um estudo de caso. Tropical Oceanography. 33(2): 192-202.

Castro, R.S. (orgs.) 2005. Educação Ambiental: repensando o espaço da cidadania. 3. Ed. São Paulo: Cortez. 207f.

Coelho-Jr, C. 2010. Gradiente de inundação pelas marés e a drenagem terrestre sobre o comportamento da salinidade intersticial de bosque de mangue de Cananeia, São Paulo, Brasil. Revista da Gestão Costeira Integrada, Itajaí, 8(2):1-10.

Cremonez, F.E.; Cremonez, P.A.; Feroldi, M.; Camargo, M.P.De; Klajn, F.F.; Feiden, A. 2014. Avaliação de impacto ambiental: metodologias aplicadas no Brasil. Revista Monografias Ambientais, 13(5): 3821-3830.

Cuzzuol, G.R.F.; Rocha, A.C. 2012. Interação do regime hídrico com as relações nutricionais em ecossistema manguezal. Acta Botanica Brasilica, 26: 11-19.

Ferreira, A.O.; Sá, J.C.De M.; Nascimento, C.G.; Ramos, F.S. 2010. Impacto de Resíduos Orgânicos em Abatedouro de Aves e Suínos na Produtividade do Feijão na Região dos Campos Gerais. Revista Verde, 5(4): 15-21.

Meireles, A.J.A.; Cassola, R.S.; Tupinambá, S.V.; Queiroz, L.S. 2007. Impactos ambientais decorrentes das atividades de carcinicultura ao longo do litoral cearense, Nordeste do Brasil. Mercator, Fortaleza, 6(12): 83-106.

Mezzaroba, O.; Monteiro, C.S. 2014. Manual de Metodologia da Pesquisa no Direito. 6ta. Ed. Rev. E atual. São Paulo: Saraiva. 367f.

Moura, H.J.T.; Oliveira, F.C. 2009. O uso das metodologias de avaliação de impacto ambiental em estudos realizados no Ceará. Pretexto, Belo Horizonte, 10(4): 79-98.

Monteiro, A.J.L.C. 2007. Legislação Ambiental. Acesso em 07 de jul. 2017.

Nascente, J.P.C.; Ferreira, O.M. 2007. Impactos socio-ambientais provocados pelas ocupações irregulars do solo urbano: Estudo de caso do loteamento serra azul. Goiania, Goiás. 91p.

Pereira, S.S.P.; Melo, J.A.B. 2008. Artigo: Gestão dos resíduos sólidos urbanos em Campina Grande, Paraíba e seus reflexos socioeconômicos. Revista Brasileira de Gestão e Desenvolvimento Regional. G\&DR, setembro/dezembro. 2008, Taubaté, São Paulo, Brasil, 4(4): 193-217.

Rech, A.U.; Rech, A. 2010. Direito urbanístico: fundamentos para a construção de um plano director sustentável na área urbana e rural. Caxias do Sul: Educs. $286 f$.

Rolim, G.S.; Camargo, M.B.P; Lania, D.G., Moraes, J.F.L. 2007. Classificação climática de Köppen e de Thornthwaite e sua aplicabilidade na determinação de zonas agroclimáticas para o estade de São Paulo. Bragantia, 66: 711-720.

Sant'anna, M. 1995. Da cidade-monumento á cidade-documento: a trajetória da norma de preservação de áreas urbanas no Brasil (1937-1900). Dissertação de Mestrado, Faculdade de Arquitetura e Urbanismo, Universidade Federal da Bahia, Salvador.

Schaeffer-Novelli, Y.; Rovai, A.S.; Coelhojr, C.; Menghini, R.P.; Almeida, R. 2012. Alguns impactos do PL no 30/2011 sobre os manguezais brasileiros. In: Comitê Brasil em Defesa das Florestas e do Desenvolvimento Sustentável (Ed.). Código Florestal e a Ciência: O que nossos legisladores ainda precisam saber. Brasília: Comitê Brasil em Defesa das Florestas e do Desenvolvimento Sustentável, 18-27.

Tommasi, L.R. 1994. Estudo de Impacto Ambiental. São Paulo, CETESB/Terragrahp, Artes e Informática. 354f.

Zancheti, S. M.; Hidaka, L. T. F. 2014. A Construção da Significância de Exemplares da Arquitetura Moderna. Olinda/PE. Centro de Estudos Avançados da Conservação Integrada. Texto para Discussão. 57, série 2 (Gestão de Restauros). 18f. 